\title{
MAPPING OF HISTORICAL HUMAN \\ ACTIVITIES IN THE SALDANHA BAY MILITARY AREA
}

\author{
Jacques Bezuidenhout \\ Faculty of Military Science, Stellenbosch University
}

\begin{abstract}
Saldanha Bay on the west coast of South Africa is surrounded by various nature reserves, military units and training sites. Over a long period of time, large parts of this semi-arid area were exposed to human activities, including military training and the preparation of forces for war. This article investigates the prospect of identifying areas where human activities took place via mapping of the variation in primordial radioactive isotopes. For this purpose, in situ gamma-ray data were obtained from selected locations around Saldanha Bay. The data were used to extract concentrations of primordial radioactive isotopes in these locations. The radioactive primordial isotope concentrations were then mapped and compared to historical evidence of human activities in these areas. The concentrations of potassium isotope showed a relationship to the height above mean sea level. Historical human activities were mainly confined to flatter regions of the area around Saldanha Bay and therefore also relate to the height above mean sea level. The potassium concentrations and the areas where human activities took place were compared and a significant relationship was found.
\end{abstract}

\section{Introduction}

The west coast of South Africa forms a rocky peninsula between St Helena Bay to the north and Saldanha Bay to the south. This outcrop is also generally referred to as the West Coast Peninsula. The underlining bedrock of the West Coast Peninsula is granite. This is clearly visible in resistant headlands on large parts of the coastline in and around Saldanha Bay. These protrusions of intrusive rocks belong to the Late Precambrian to Cambrian Cape Granite Suite. ${ }^{2}$

Scientia Militaria, South African Journal of Military Studies, Vol 40, Nr 2, 2012, pp. 89-101 doi: $10.5787 / 40-2-998$
Granite outcrops are also visible on most of the hills on the West Coast Peninsula, which include those surrounding Saldanha Bay. The upper layers of soil in the alluvial fans on the slopes of these hills are therefore mainly 
broken down granite rock. Some of the deeper layers of sediment also date back to periods when the sea levels were higher and illustrate various palaeoshorelines. ${ }^{3}$ Paleontological marine sediment is therefore common in most of the quarries around Saldanha Bay.

Primordial radioactive elements consist of uranium $\left({ }^{238} \mathrm{U}\right)$, thorium $\left({ }^{232} \mathrm{Th}\right)$ and potassium $\left({ }^{40} \mathrm{~K}\right)$ of which potassium is by far the most abundant. ${ }^{4}$ Natural potassium constitutes about $2,4 \%$ of the mass of the earth and is present at in clays, feldspars and micas. ${ }^{5}$ The natural radioisotope ${ }^{40} \mathrm{~K}$ has an abundance of $0,0119 \%$ of all natural potassium, whereas all natural uranium and thorium isotopes are radioactive. In situ gamma-ray measurements of uranium and thorium therefore produce direct values for the concentrations of these elements in material. Natural potassium concentrations are however deduced from in situ gamma-ray measurements of the ${ }^{40} \mathrm{~K}$ radioisotope. ${ }^{6}$

Primordial radioactive elements materialise in most natural material and granite rock is no exception. ${ }^{7}$ In nature, potassium distributes as a mono-charged positive ion. These potassium salts are highly soluble and when in solution, it is very mobile. ${ }^{8}$ The potassium in alluvial fans consequently starts to weather away as soon as it is exposed to terrestrial weathering. This then results in variations in potassium concentrations. Because of this, potassium concentrations would generally correlate with height when slopes of alluvial fans are investigated. Lowlying areas, like salt marshes, subsequently display high concentrations of potassium while high-lying areas would demonstrate lower concentrations of potassium. ${ }^{9}$

When human activities take place in an area, the top soil is disrupted, resulting in exposure of deeper-lying soil. Weathering might change the composition of this newly exposed soil. This article investigates the possibility that this may lead to a decrease in the potassium concentration. By measuring the potassium on slopes or in flat-lying areas, divergence in the expected potassium concentration may then indicate previous disruption in the top soil. Such changes may be attributed to a number of reasons, and one of these may be historical human activities in archaeological sites.

In situ gamma-ray measurements have been used in a previous study by Moussa to explore an archaeological site in the Tell Abu Seef area of Egypt. ${ }^{10}$ The potassium levels for two different areas were compared during that study. The areas matched the building remains of the archaeological site and the surrounding sediments. The highest concentrations of potassium were detected in the remains of 
the walls, which consisted of muddy material. Lower values of potassium were found in the surrounding media which consisted of sediments. The fundamentals of the study by Moussa however differ from this study since building material was transported into that archaeological site, whereas colluvial processes only influenced natural material in this study area.

\section{History of the study area}

The geographical nature of Saldanha Bay makes it an ideal harbour and it was for that reason used as an assembly point for the formation of naval convoys during the Second World War. ${ }^{11}$ This strategic nature of the bay motivated military occupation and subsequent fortification of the northern and southern headlands (see Figure 1).

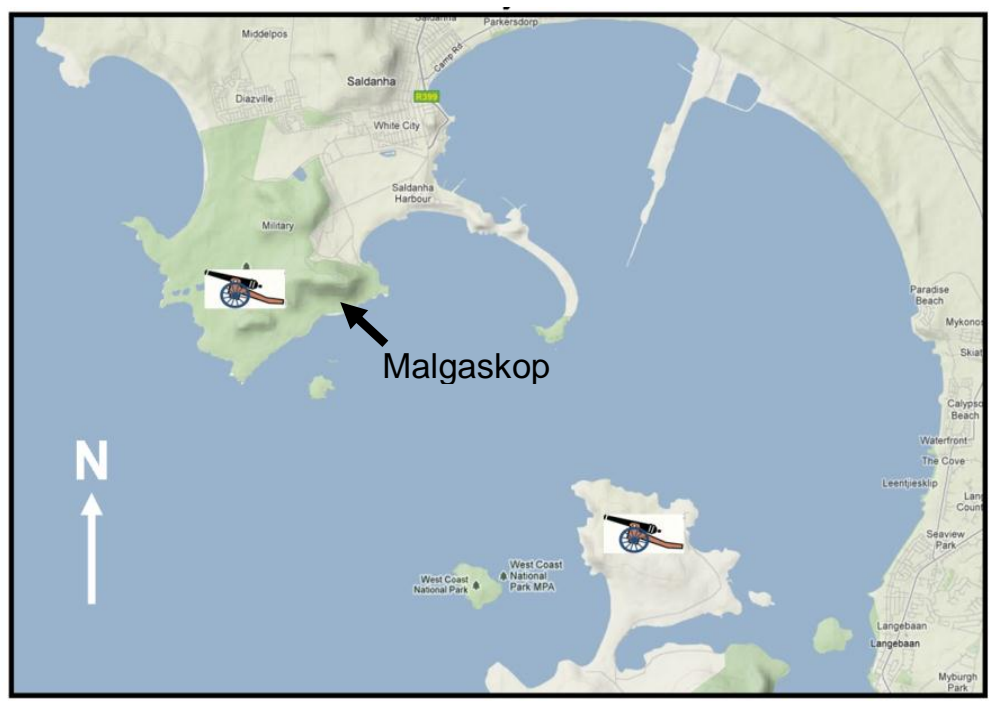

Figure 1: A map of Saldanha Bay indicating the surrounding nature reserves, coloured green. The two military areas that date from the Second World War are indicted by gun iconc. Malgaskop on the northern headland is also marked.

These areas have ever since been occupied by the military and are currently managed as military nature reserves. These nature reserve areas are however also still used for sporadic military training, but under strict environmental guidelines. 
The northern headland of Saldanha Bay is dominated by three hills of which Malgaskop is the highest. Due to its height and the prime location, Malgaskop was chosen as nucleus of a naval gun battery that operated during the Second World War. Various structures were therefore erected on and around Malgaskop. The steeper slopes of Malgaskop were understandably avoided and therefore stayed relatively untouched. Large areas of land were also cleared of fynbos and dirt roads were constructed to link the different military structures. Many of the structures are still intact today but most of the dirt roads have been overgrown by fynbos. These historical military activities had a large impact on the natural environment on and around Malgaskop.

The flat-lying areas around Malgaskop were also used for agriculture. The natural fynbos was cleared to make room for crop fields, and terraces were also formed through earthworks to prevent soil erosion. At present, the fynbos is gradually reclaiming the fields but most of the terraces are still fairly visible, especially when investigating aerial photographs (see Figure 3). Some invasive plants species are also prevalent in the previously cultivated areas.

\section{Methodology}

Malgaskop, which is bordered by the ocean on the east and the south, was selected as research site for in situ gamma-ray measurements. The prevailing wind direction at Saldanha Bay is southerly, and it is therefore assumed that Malgaskop is rarely exposed to aeolian deposits. ${ }^{12}$ The soil in the alluvial fans of Malgaskop was therefore treated as weathered granite rock. Granite has relatively high concentrations of natural radioactive isotopes and the potassium concentrations can even be as high as $5 \% .^{13,14}$ The soil on Malgaskop therefore also consists of high concentrations of potassium.

Four transects that run up different directional slopes of Malgaskop were examined. Three of these transects (N,W and $\mathrm{S}$ ) originated at the same point in an alluvial fan, while the fourth transect (E) originated close to the ocean amongst marine sediment (see Figure 2). Gamma-ray spectra were obtained in situ at different points on these transects. A NaI $(T l)$ detector $(7,62 \times 7,62 \mathrm{~cm})$ coupled to a scintiSPEC multi-channel analyser (MCA) was used to record the gamma-ray spectra. The scintiSPEC MCA that is produced by ICX Technologies has a USB connection to a laptop computer through which operating voltage is obtained and signal communication takes place. A Garmin GPS map 76 was used to determine the latitude and the longitude for each measuring point, and the height above mean 
sea level (msl) was acquired by means of a theodolite that was positioned at the base of each transect. The accuracy error of the GPS was between $5 \mathrm{~m}$ and $15 \mathrm{~m}$.

A window analysis technique was used to extract the count rates for the three different primordial isotopes. Specific gamma-ray peaks in the spectra were associated with each of the three primordial isotopes and the net number of counts under these peaks was calculated by fitting a gauss function on the peaks. The spectra from all the measurements were analysed by extracting the net counts in the $1460 \mathrm{keV}$ gamma-ray peak and the $1764 \mathrm{keV}$ gamma-ray peak of the ${ }^{40} \mathrm{~K}$ radionuclide as well as the $2615 \mathrm{keV}$ gamma-ray peak. The activity of potassium was calculated from the characteristic ${ }^{40} \mathrm{~K}$ photo peak in the spectra according to a method described by Maleka. ${ }^{15}$ The $2615 \mathrm{keV}$ gamma-ray peak that is associated with ${ }^{208} \mathrm{Tl}$ decay was also examined, and the relative activity for thorium was extracted. The $1764 \mathrm{keV}$ gamma-ray peak that is associated with ${ }^{214} \mathrm{Bi}$ decay was employed to extract the concentration of uranium. The intensity of the ${ }^{214} \mathrm{Bi}$ decay was very low $(15,4 \%)$ and the net peak analysis method therefore did not provide sufficient data to investigate the uranium concentrations. These calculations were all done by means of the winTMCA32 acquisition and analysis software that is supplied with the scintiSPEC MCA.

The efficiency calibrations measurements of the system were done at a standard radiation reference pad of the Nuclear Energy Corporation of South African (NECSA) and with 99,6\% pure potassium chloride according the method describe by Chiozzi and others. ${ }^{16}$ The detector was buried in the soil during all the in situ measurements. The detector had to be submerged in the calibration material in order to accommodate for geometry and to produce a symmetrical setup with that of the in situ measurements. The detector was covered with the potassium chloride and placed in a hole in the centre of the reference pad at NECSA while recording the calibration spectra. These calibration spectra were use to extract efficiency parameters for the detector during in situ measurements. The net counts under the three peaks were then correlated to the known activities of the specific isotopes in the pad and the potassium chloride, and efficiency parameters were extracted for each of the isotopes. The efficiency parameter for potassium was therefore verified by two independent measurements, which resulted in a more reliable efficiency parameter for potassium. The potassium concentrations were consequently expressed in becquerel per kilogram, whereas the thorium and uranium were expressed as relative concentrations (count/second). 


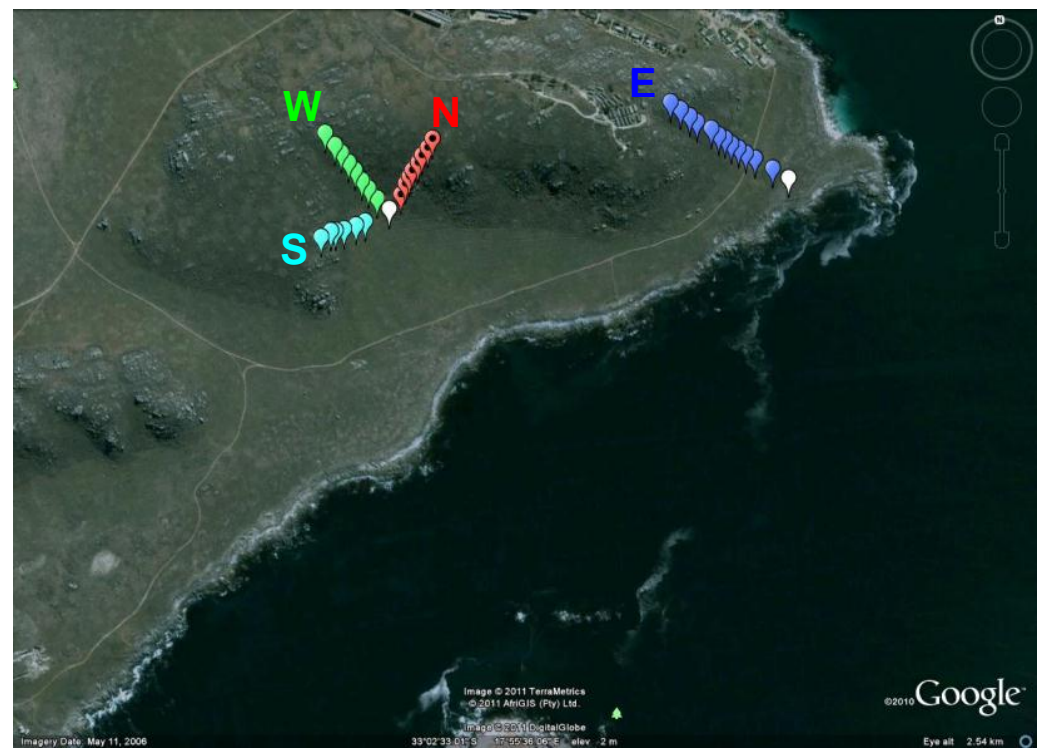

Figure 2: A Google Earth image of Malgaskop indicating the points on the four transects that were measured. The measured points of the four transects are marked blue, green, red and turquoise and represent transects E, W, N and S respectively.

The system energy calibrations were done in situ by means of standard ${ }^{60} \mathrm{Co}$ and ${ }^{137} \mathrm{Ce}$ test sources. The energy calibrations were performed in the energy range from $662 \mathrm{keV}$ to $1332 \mathrm{keV}$. Each of the in situ spectra was acquired for periods of at least 10 minutes. The $\mathrm{NaI}(T l)$ detector was buried $30 \mathrm{~cm}$ underneath the surface of the soil for the acquisition of each spectrum.

The measurements of the concentrations of potassium and thorium showed a relation to height above mean sea level (msl). The measured concentrations of the potassium and thorium were therefore plotted against height above msl and conclusions were drawn (see Figures 3 and 7).

\section{Results}

The potassium concentrations on all the transects showed an increase with height above msl until it reached maximum concentrations at heights of $34 \mathrm{~m}, 48 \mathrm{~m}$, $42 \mathrm{~m}$ and $29 \mathrm{~m}$ above $\mathrm{msl}$ for transects E, W, N and S, respectively (See Figures 3). Thereafter the potassium concentrations constantly decreased with an increase in height above msl. An abrupt decrease in the concentrations for the $\mathrm{E}$ and $\mathrm{S}$ transects 
at $62 \mathrm{~m}$ and $34 \mathrm{~m}$ respectively was noticeable. The top measurement was taken between granite outcrops at the top of Malgaskop at a height of $109 \mathrm{~m}$ above msl.

The statistical error for each data point was determined according to the method described by Knoll. ${ }^{17}$ The average statistical errors were then calculated for all the thorium count rates and potassium concentrations, and were found to be 0,74 counts per second and 131,5 Bq/kg, respectively. These average statistical errors are only indicated on last data points of each graph (see Figures 3 and 7).

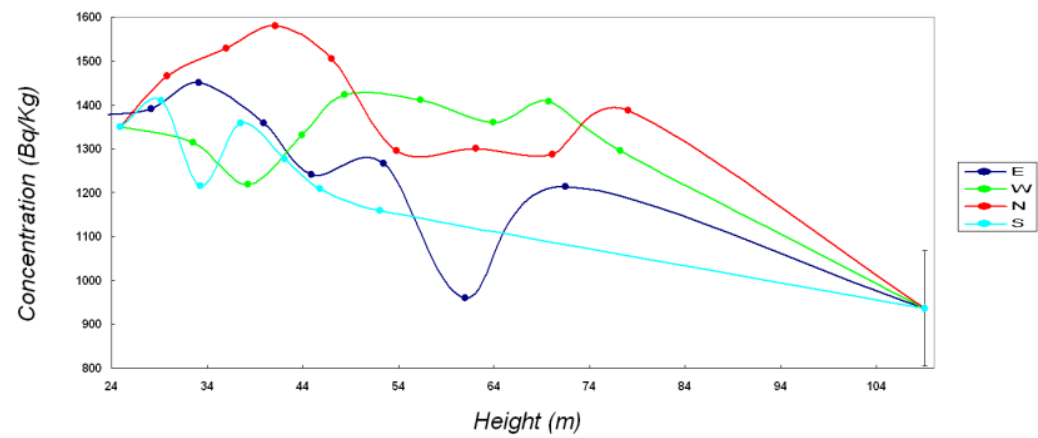

Figure 3: Potassium concentrations plotted as a function of height above msl. The points on four curves show the concentration measurements along the four transects where blue, green, red and turquoise represent transects $\mathrm{E}, \mathrm{W}, \mathrm{N}$ and $\mathrm{S}$ respectively. The curves are smoothed through the data points to help guide the eye.

Transects $\mathrm{W}, \mathrm{N}$ and $\mathrm{S}$ originated at the same point in an alluvial fan on the southern slope of Malgaskop. The origin of these transects was in an area that was cultivated in the past. Terraces to prevent soil erosion and other evidence of these agricultural activities are clearly visible on the Google Earth image in Figure 4. The slope of the hill increases as transects are tracked up the hill. As soon as the slope of the hill becomes steep and rocky, evidence of historical agricultural activities discontinues. It was therefore assumed that the soil and the natural fynbos were left undisturbed on these steep and rocky slopes of the hill. The limits of the agricultural area were estimated by means of agricultural evidence on the ground and inspections of the aerial photographs. Figure 5 displays the slope of each transect, and the estimated limits of the agricultural area are indicated by dashed lines in this graph. The estimated limits are colour-coded similar to the colours of the plots of the transects. 


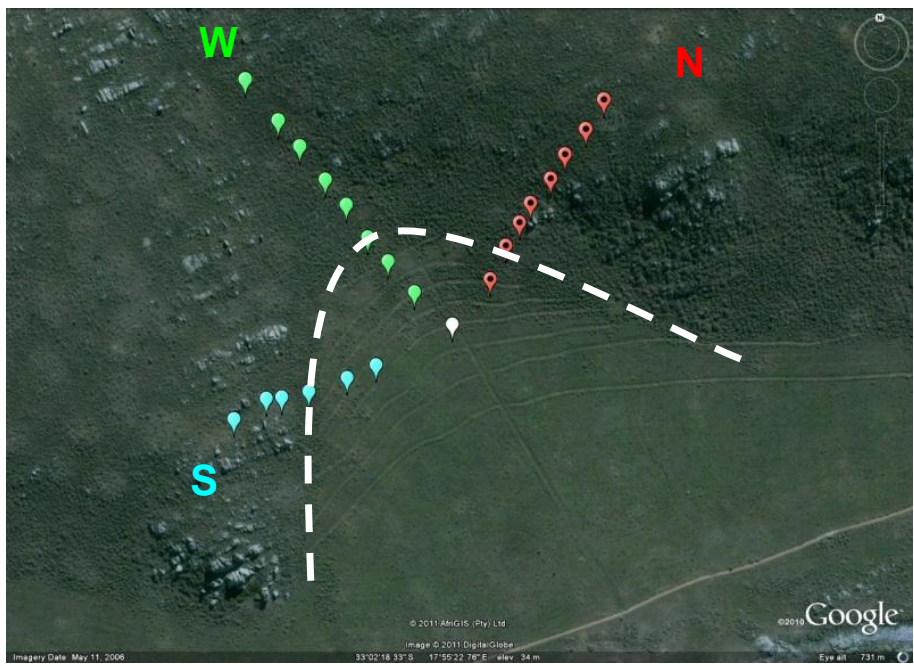

Figure 4: A Google Earth image of an alluvial fan on the southern slope of Malgaskop, indicating points on the three selected transects that were measured. The measured positions of the three transects are marked green, red and turquoise and represent transects $\mathrm{W}, \mathrm{N}$ and $\mathrm{S}$ respectively. Evidence of earthworks and deforestation, which indicates human activities, is clearly visible on the image. The estimated border of these human activities is marked by the white dashed line.

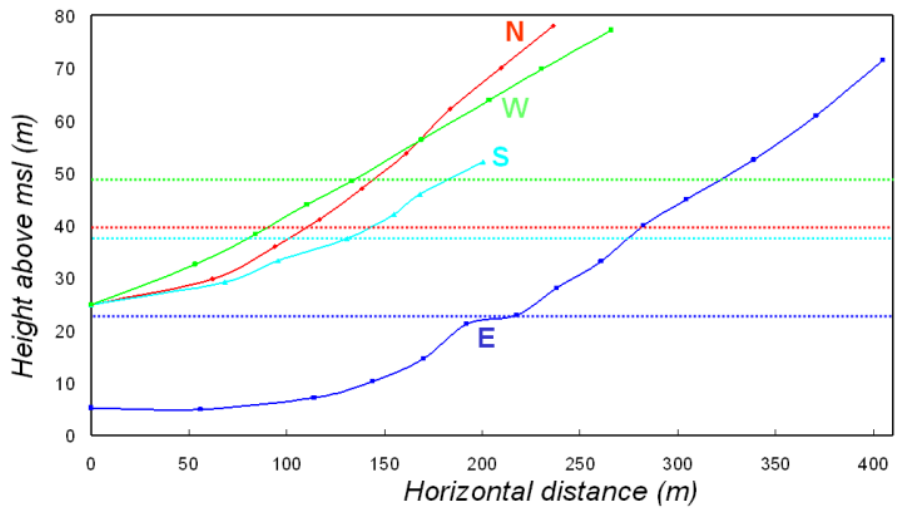

Figure 5: The slopes of the four transects given as height above msl. The dashed lines on each transect indicate the estimated borders between the natural fynbos areas and the areas where historical human activities took place. The four curves indicate the four transects with blue, green, red and turquoise representing transects $\mathrm{E}, \mathrm{W}, \mathrm{N}$ and $\mathrm{S}$ respectively. 
Transect E originated amongst marine sediment next to the ocean and ran up the eastern slope of Malgaskop. Various Second World War bunkers were erected on this slope and these were linked by dirt roads, power cables and fences. The natural environment on this slope was severely disrupted by military activities during the Second World War. The flat section on the slope of this transect at a height of $20 \mathrm{~m}$ above msl (See Figure 5) was treated as a road. This road linked several of the bunker systems. This was confirmed by an inspection of Second World War photographs that were obtained from the archives of the South African Military Academy. The highest point where human interference with the natural fynbos and top soil disruptions took place was therefore taken on the upper boundary of this road. It is however difficult to categorically state that no human activities took place higher up on this slope of the hill.
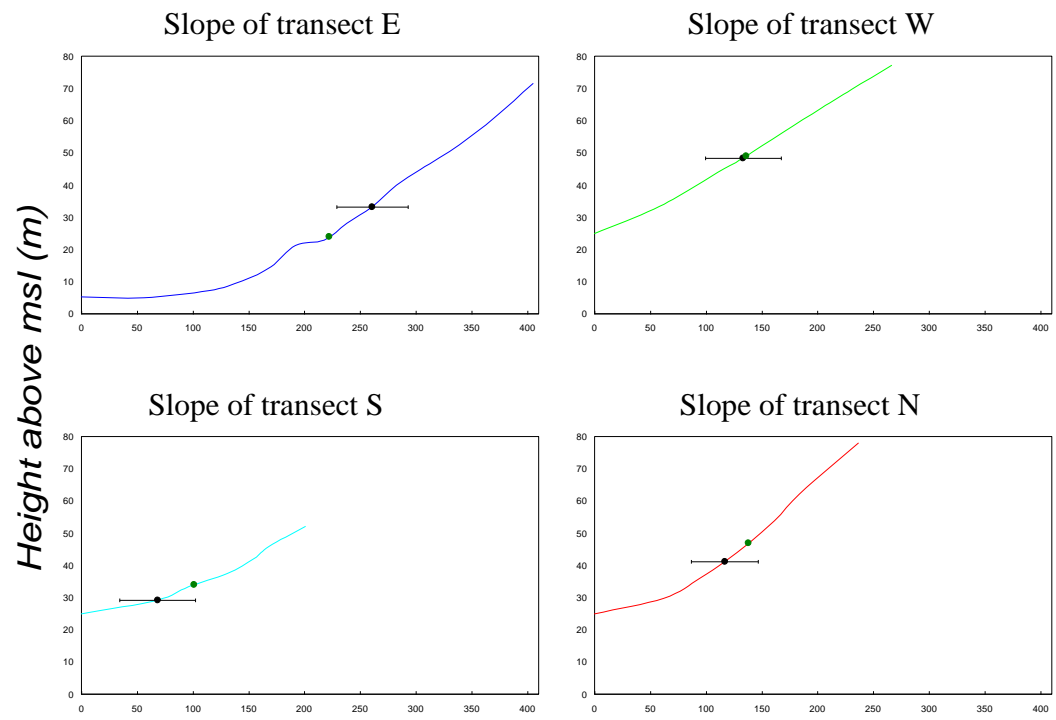

Horizontal distance $(m)$

Figure 6: The slopes of the four transects given as height above msl. The green markers indicate the borders between the natural fynbos areas and the areas where human activities took place. The black markers show the position of the point where the highest concentration of potassium was measured with the error bars indicating the uncertainly due to the inaccuracy of the GPS-determined positions. 
The slopes of the four transects are individually plotted in Figure 6. The highest point where human interference with the natural environment took place is indicated on each curve by means of a green marker. The point where the potassium concentration reached a maximum on each of the transects is indicated by a black marker. The errors on each of these maximum potassium concentration points were taken as the average of the vertical distance between the various sample points on each transect, and these are shown in the graphs.

The thorium concentrations showed two tendencies that were related to different slopes of the Malgaskop hill. The $\mathrm{W}$ and $\mathrm{S}$ transects showed little relationship to the height above msl, but the $\mathrm{E}$ and $\mathrm{S}$ transects demonstrated a clear peak in the thorium concentrations at $54 \mathrm{~m}$ above msl (See Figure 7). Similar to the potassium graphs, abrupt decrease also occurred in the E transect of the thorium concentrations.

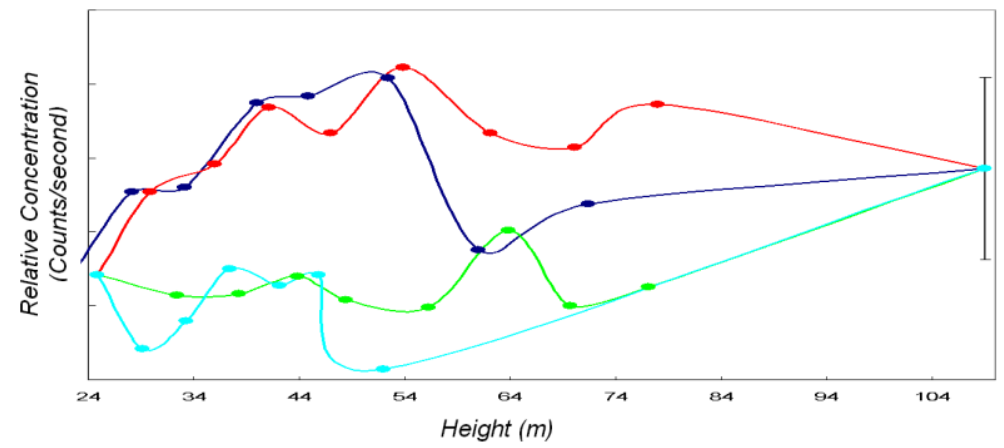

Figure 7: Thorium concentrations plotted as a function of height above msl. The points on the curves show the concentration measurements along the four transects where blue, green, red and turquoise represent transects $\mathrm{E}, \mathrm{W}, \mathrm{N}$ and $\mathrm{S}$ respectively. The curves are smoothed through the data points to help guide the eye.

\section{Discussion}

The flat-lying areas surrounding Malgaskop were developed and cleared for agriculture and later for military preparations during the Second World War. ${ }^{18}$ The steeper slopes of Malgaskop were not developed. The general slope of Malgaskop hill increases rapidly between $30 \mathrm{~m}$ to $50 \mathrm{~m}$ above msl and this corresponds well with the borders between the historically cleared and the natural undisturbed fynbos areas. It was therefore assumed that the areas above these borders were only exposed to natural phenomena. The dashed lines in Figure 5 
indicate the heights at which these transects cross these borders. The areas higher than the borders were mainly exposed to weathering that would have resulted in the downhill transportation of material. Potassium is highly soluble and would be transported downhill over time with a resultant increase in the potassium concentration as one descends the hill. This is evident in the trend of the potassium concentrations in natural undisturbed fynbos areas.

The areas lower than the borders were exposed to military activities and agriculture, which included deforestation and earthworks. These activities disrupted the top soil and broke the water- and wind-resistant crust of the soil. The soil in these areas was therefore additionally exposed to weathering, resulting in the consequent removal of even more potassium. It was therefore predicted that the potassium concentrations would decrease with a decrease in height above msl in these disrupted areas. This theory is supported by the trend of the potassium concentrations being lower than the borderlines between historical human activities and the natural fynbos areas. This is contrary to the occurrence in the natural undisturbed areas and results in a peak of the potassium concentrations at the borders between the disturbed and undisturbed natural areas. The borders of historical human interference in a natural area can therefore be estimated by extraction of the potassium concentration peaks from in situ gamma-ray measurements on the slopes of soil-covered hills or mountains.

The abrupt decrease in the E and $\mathrm{S}$ transects at $34 \mathrm{~m}$ and $62 \mathrm{~m}$ above $\mathrm{msl}$ respectively, can be attributed to outcrops of granite rock, which form the foundation of the underlying geological formation. ${ }^{19}$ Physical evidence of granite rock was also found at these points whilst the in situ measurements were done. Abrupt decreases also occur in the $\mathrm{E}$ and $\mathrm{S}$ transects of the thorium concentrations curves, similar to those in the potassium concentrations curves. This further supports the presence of granite outcrops underneath the tops soil at those points.

The results of the thorium concentration variations were however inconclusive. A similar trend as in the potassium however seems to appear in the $\mathrm{E}$ and $\mathrm{N}$ transects. It is expected that thorium and uranium would be less prone to transportation when exposed to weathering, because of the relatively high specific mass of these minerals. The concentrations of these two minerals are also much lower than that of potassium, which also makes it difficult to detect variation, especially when taking the statistical error into consideration. 


\section{Conclusion}

It has been shown that human activity can modify the natural concentrations of radioactive isotopes by the release of residues and effluents into the environment. ${ }^{20}$ An investigation of the changes in the concentration of these isotopes caused by other human activities has however not been done. Of all the primordial isotopes, potassium is the most abundant and most prone to transportation; consequently, potassium provides the best gauge to utilise in such investigations. Concentrations of potassium levels were therefore taken over a large area that varied in height above msl and that crossed boundaries of human interferences. The relation between these measured concentrations and height above msl was then determined and correlated with the boundaries of the areas where human activities took place.

The results of measured data were consistent with the model that predicts potassium concentrations to decrease with an increase in human activity. While the results of potassium measurements proved to be consistent with the model, further investigation is needed to refine the model and also to include the other primordial radioactive elements. More measurements are currently being planned at a second site with similar physical characteristics. Window analysis of the in situ measured spectra did not give sufficient data with which uranium concentrations could be extracted. Full spectrum analysis of the spectra may provide improved values for the uranium concentration as well as for the other primordial radioactive isotopes. ${ }^{21}$

\section{Endnotes}

${ }^{1}$ The author would like to thank Lieutenant AP Geyser of the South African Navy for his assistance in preparing the maps and assistance while conducting the field measurements. The author would also like to extend his appreciation to his colleagues in the Military Geography Department in the Faculty of Military Science for their help and collaboration on this project.

${ }^{2}$ Villaros, A. "Petrogenesis of S-type Granite with Particular Emphasis on Source Processes: The Example of the S-type Granite of the Cape Granite Suite". Phd Dissertation. Stellenbosch University. 2010.

${ }^{3}$ Franceschini, G \& Compton, JS. "Aeolian and marine deposits of the Tabakbaai quarry area, Western Cape, South Africa”. South African Journal of Geology. 107. 2004. 619-632.

${ }^{4}$ De Meijer, RJ. “Heavy minerals: From 'Edelstein' to Einstein”. Journal of Geochemical Exploration 62. 1998. 81-103.

${ }^{5}$ Van der Graaf, ER, Koomans, RL, Limburg, J \& De Vries, K. "In situ radiometric mapping as a proxy of sediment contamination: Assessment of the 
underlying geochemical and -physical principles". Applied Radiation and Isotopes 65/5. 2007. 619-633.

${ }^{6}$ De Meijer op. cit.

${ }^{7}$ Macdonald, WG, Rozendaal, A \& De Meijer, RJ. "Radiometric characteristics of heavy mineral deposits along the west coast of South Africa". Mineralium Deposita 32. 1997. 371-381.

${ }^{8}$ De Meijer op. cit.

${ }^{9}$ De Groot, AV. "Salt-marsh sediment - Natural $\gamma$-radioactivity and spatial patterns". Dissertation. Rijksuniversiteit Groningen, 2009.

${ }^{10}$ Moussa, M. "Gamma-ray spectrometry: A new tool for exploring archaeological sites - a case study from East Sinai, Egypt". Journal of Applied Geophysics 48. 2001. 137-142.

${ }^{11}$ Burman, J \& Levin, S. The Saldanha Bay story. Cape Town and Pretoria: Human \& Rousseau, 1974.

${ }^{12}$ Franceschini \& Compton op. cit.

${ }^{13}$ Llope, WJ. "Activity concentrations and dose rates from decorative granite countertops". Journal of Environmental Radioactivity. 102. 2011. 620-629.

${ }^{14}$ Baranwal, VC, Sharma, SP, Sengupta, D, Sandilya, MK, Bhaumik, BK, Guin, R $\&$ Saha, SK. "A new high background radiation area in the geothermal region of Eastern Ghats Mobile Belt (EGMB) of Orissa, India". Radiation Measurements 41. 2006. 602-610.

${ }^{15}$ Maleka, PP. "In-situ element analysis from gamma-ray and neutron spectra using a pulsed-neutron source". Dissertation. Rijksuniversiteit Groningen, 2010.

${ }^{16}$ Chiozzi, P, De Felice, P, Fazio, A, Pasquale, V \& Verdoy, M. "Laboratory application of $\mathrm{NaI}(\mathrm{Tl}) \gamma$-ray spectrometry to studies of natural radioactivity in geophysics". Applied Radiation and Isotopes 53. 2000. 127-132; Corner, B, Toens, PD, Richards, DJ, Van As, D \& Vleggaar, CM. The Pelindaba facilities for calibrating radiometric field instruments. Publication of Atomic Energy Board, No. PEL-268, April 1979, Pretoria.

${ }^{17}$ Knoll, GF. Radiation detection and measurement, $4^{\text {th }}$ ed. New York: Wiley, 2010.

${ }^{18}$ Burman \& Levin op. cit.

${ }^{19}$ Villaros, A. op. cit.

${ }^{20}$ Montes, ML, Mercader, RC, Taylor, MA, Runco, J \& Desimoni, J. “Assessment of natural radioactivity levels and their relationship with soil characteristics in undisturbed soils of the northeast of Buenos Aires province, Argentina". Journal of Environmental Radioactivity 105. 2012. 30-39.

${ }^{21}$ Hendriks, PHGM, Limburg, J \& De Meijer, RJ. "Full-spectrum analysis of natural gamma-ray spectra”. Journal of Environmental Radioactivity 53. 2001. 365380 . 